\title{
The Effect of Health Beliefs on the Compliance of Periodontal Patients with Oral Hygiene Instructions
}

\author{
Matthias K. Kühner* and ${ }^{\dagger}$ Peter B. Raetzke ${ }^{\dagger}$
}

\begin{abstract}
Problems of Patient COMPLIANCE IN periodontics are evident. This study explored factors which may contribute to the degree of adherence. Using the "Health Belief Model" a questionnaire was constructed and administered to 120 patients of the Department of Periodontology, University of Frankfurt Dental School. Compliance of these patients during the hygienic phase was assessed using a bleeding index. The data set for statistical evaluation comprised 96 patients. The loss was due to missing of appointments and incomplete questionnaires. There was no significant correlation between patient compliance on the one hand and sociodemographic variables (age, sex, family status), disease parameters, and the health beliefs "susceptibility," "barriers," "dentist-patient-relationship," and "experience with therapy" on the other hand. "Motivation," "seriousness," "benefits," "experience with affected organ," and tooth-loss-index were significant predictors with Spearman correlation coefficients running from 0.17 to 0.32 . When the predictor variables were combined the coefficient was 0.59 . This study further supports the assumption that health beliefs play a significant role in the determination of health related behavior.
\end{abstract}

Factors affecting patient compliance have gained considerable interest in dentistry over the past years. That has been the result of the perception that compliance has a decisive influence on the outcome of almost every therapy. This is especially true for periodontics. The degree to which a given patient complies with oral hygiene instructions is of more importance than the choice of any special treatment method. ${ }^{1-4}$ On the other hand, many authors emphasize the lack of a reliable method to improve patient compliance. ${ }^{4-11}$ Sheiham $^{12}$ confirms this view by saying: "I have a major criticism of all the work that has been done on biology and treatment of periodontal disease however painstaking and accurate it has been. My criticism is that such research is of no practical use unless supplemented by even more detailed painstaking and accurate research on health and social behavior."

As Rosenstock ${ }^{13}$ states: "Efforts to modify behavior will ultimately be more successful if they grow out of an understanding of causal processes." Thus, theoretical models analyzing patient behavior are necessary to understand the complex relationships underlying human behavior. The "Health Belief Model" (HBM) is

\footnotetext{
* Department of Periodontology, University of Frankfurt, Dental School and Clinic "Carolinum," Frankfurt, West Germany. Presently graduate student in periodontics, University of Michigan, Ann Arbor.

${ }^{\dagger}$ Department of Periodontology, University of Frankfurt, Dental School and Clinic "Carolinum," Frankfurt, West Germany.
}

one of the most elaborated concepts. In its original version it consisted almost exclusively of intra-individual factors, thus dealing with the subjective world of the patient and not with the objective world of the physician or the dentist. The variables included are: perceived seriousness, perceived susceptibility, perceived barriers, and perceived benefits. ${ }^{13}$ Of these, susceptibility and seriousness define a psychological state of readiness to act, whereas barriers and benefits provide a preferred path of action. Besides, a cue, either internal (e.g. perception of bodily states) or external (e.g. interaction with an ill person or a media campaign), is considered necessary to trigger health-related behavior. Since the introduction of the HBM several extensions have been suggested to improve its explanatory power. The variable "health motivation" (i.e. the intention of the patient to comply and his concern about health matters in general) was added as well as modifying factors such as quality of dentist-patientrelationship, experience with therapy, and influence by family and peer groups. ${ }^{14}$

The HBM has proved to be a rather reliable predictor of patient compliance in medicine (for review see Haynes, ${ }^{15}$ Becker, ${ }^{16}$ Eraker et al. ${ }^{17}$ ). Studies applying the HBM to dental compliance problems have not yielded unequivocal results (for review see Kühner and $\mathrm{Raetzke}^{18}$ ). This is largely due to inadequate-study designs and the problem that "health beliefs are only a part of the social matrix in which behavior occurs." 19 However, significant correlations between health beliefs 
and compliance prevail as far as health behavior of adults is concerned.

\section{MATERIAL AND METHODS}

\section{Study Group}

One hundred and twenty patients entering the Department of Periodontology, University of Frankfurt Dental School and Clinic, were selected for the study. Twenty four persons were excluded from the investigation: 14 of these because they did not keep follow-up appointments and 10 patients because they left out more than 10 of the questionnaire items. Thus, the study population comprised 96 patients, 49 females and 47 males. The average age was 40.3 years, with a standard deviation of 11.3.

\section{STUDY DESIGN}

When first visiting the Department of Periodontology, the patients' periodontal condition was assessed. Periodontal pockets were measured to the nearest millimeter with a periodontal probe (Hu Friedy PCP 11). The gingival condition was evaluated by assessing the percentage of gingival units with bleeding provoked by the probing procedure (percentage of bleeding gingival units: PBGU).

After baseline examination the patients were informed they had periodontal disease. The nature of periodontitis, the relationship between oral hygiene, plaque, and tissue inflammation as well as the recommended therapy were explained briefly. Then a standardized questionnaire was administered to all patients. Participation in the study was left to the patients' discretion and anonymous data processing was guaranteed.

The following hygienic phase (preceding cause-related periodontal therapy) comprised supragingival debridement, and elimination of plaque retentive factors such as overhanging restorations and carious lesions. Furthermore, patients were instructed in proper oral hygiene techniques comprising modified Bass method and use of dental floss or interproximal brushes. They were motivated to improve their oral hygiene by explaining to them the role of plaque in the etiology of periodontal disease and by describing the possible outcome if they did not comply. Additionally, their success in applying the new techniques was supervised using a plaque-index $\left(\mathrm{API}^{20}\right)$ at every treatment session. The result was discussed with the patients thus providing feedback to them about the quality and quantity of their oral home care. No other specific method was used to reinforce compliance.

The number of appointments was chosen according to patient needs but was restricted to four at most. Frequency distribution is shown in Table 1.

At the termination of the hygienic phase the patients' periodontal condition was reevaluated. An average of 41 days with a standard deviation of 9.3 passed between baseline examination and reevaluation.

\section{THE QUESTIONNAIRE}

The questionnaire included 28 health belief-related statements and a printed four-step rating-scale ranging from "strongly agree" to "strongly disagree". Thus a subject centered approach ${ }^{21}$ was chosen to explore the health beliefs. An additional question asked for barriers to proper oral hygiene. Patients were free in formulating answers to this item.

A pilot study with 20 persons was carried out to examine if any problems emerge with regard to filling out the questionnaire. As a consequence minor corrections became necessary.

Table 2 shows the number of items referring to any specific health belief. The aspect "experience with affected organ" was added as a result of a preceding expert interview with periodontists.

\section{DATA ANALYSIS}

Independent variables included health beliefs, age, sex, family status, number of missing teeth, average probing depth, and Tooth-Loss-Index (TLI). TLI was computed by grouping patients due to having lost more or less teeth than the average individual in their age group. $^{22}$

Compliance was defined analytically as improvement in oral hygiene on baseline values. Operationalization derived by computing the relative change of $\mathrm{PBGU}$ (RPBGU). Hence the difference in PBGU values between baseline and reevaluation was calculated and divided by the baseline value.

For statistical analysis of the data, the Spearman correlation coefficient was used to assess the relationship between individual factors.

Table 1

Frequency of Appointments

$\begin{array}{lrrr}\text { Number of appointments } & 2 & 3 & 4 \\ \text { Frequency (no. of patients) } & 48 & 40 & 8\end{array}$

Table 2

Frequency of Questionnaire-Items Referring to Any Specific Health Belief

\begin{tabular}{lc}
\hline \multicolumn{1}{c}{ Health beliefs } & No. of items \\
\hline Motivation & 5 \\
Susceptibility & 3 \\
Severity & 3 \\
Barriers & 7 \\
Benefits & 3 \\
Dentist-patient-relationship & 3 \\
Experience with therapy & 3 \\
Experience with affected organ & 1 \\
\hline
\end{tabular}




\section{RESULTS}

Between baseline and reevaluation PBGU values decreased (see Table 3), the average improvement being $51.2 \%$

For further computation, relative PBGU values were grouped as shown in Table 4.

No significant correlation was found between compliance and 19 of the questionnaire items. Statistical analysis revealed no association between compliance and sociodemographic variables (age, sex, family status). The disease parameters "number of missing teeth" and "probing pocket depth" were not predictors. Only the TLI was significantly correlated with compliance.

The significant predictors are shown in Table 5 together with the Spearman correlation coefficients.

With regard to the specific health beliefs the result was as follows (numbering refers to Table 5).

Table 3

$P B G U^{*}$ Values

\begin{tabular}{lcc}
\hline & Mean & SD \\
\hline PBGU at baseline & $71.3 \%$ & 29.2 \\
PBGU at reevaluation & $36.8 \%$ & 24.5 \\
Relative PBGU values & $51.2 \%$ & 32.1 \\
\hline
\end{tabular}

* Percentage of bleeding gingival units.

Table 4

Grouping of RPBGU* Values

\begin{tabular}{ccc}
\hline Group & Relative PBGU & N \\
\hline 1 & $76-100 \%$ & 18 \\
2 & $75-51 \%$ & 29 \\
3 & $50-26 \%$ & 24 \\
4 & $<26 \%$ & 25 \\
\hline
\end{tabular}

* Relative percentage of bleeding gingival units.

Table 5

Significant Predictors

\begin{tabular}{lr}
\hline \multicolumn{1}{c}{ Predictor } & \multicolumn{1}{c}{$\Gamma s$} \\
\hline 1) Loss of teeth decreases quality of life. & $0.32 *$ \\
2) I often worry whether I am really living in a & $0.31^{*}$ \\
healthy way. & \\
3) I would intensively cooperate in a program & $0.29 \dagger$ \\
$\quad$ to improve my oral hygiene. & $0.27 \dagger$ \\
4) I would be very much impaired by the con- & \\
sequences of caries or periodontitis. & $0.23 \ddagger$ \\
5) It is important for my job to have healthy & \\
and beautiful teeth. & $-0.19 \ddagger$ \\
6) TLI & $0.18 \ddagger$ \\
7) Poor oral hygiene leads to caries and perio- & \\
dontitis anyway. & $0.17 \ddagger$ \\
8) I will follow the directions of the dentist. & $0.17 \ddagger$ \\
9) If I do not keep good oral hygiene, I will get & \\
caries or periodontitis soon. & \\
10) I feel well in my mouth. &
\end{tabular}

$\Gamma \mathrm{s}=$ Spearman correlation coefficient.

* Statistically significant at $\mathrm{P}<0.001$.

$\dagger$ Statistically significant at $\mathrm{P}<0.01$.

$\ddagger$ Statistically significant at $\mathrm{P}<0.05$. -four out of five items exploring "motivation" were significant predictors (numbers 2, 3, 5, 8).

-two out of three items exploring "seriousness" were significant predictors (numbers 1,4 ) with relatively high correlation coefficients.

-two out of three items exploring "benefits" were significant predictors (number 7,9). However, correlation coefficients happened to be relatively low.

-the one item exploring "experience with affected organ" was significantly correlated with compliance (number 10 ).

-none of the items exploring "susceptibility" "barriers," "dentist-patient-relationship," "experience with therapy" was a reliable predictor.

In order to combine the predictive power of the significant independent variables, an Integrated-Predictor-Variable (IPV) was computed. For the first step the 10 significant independent variables (questionnaire items and TLI) were considered separately. For each of these variables the sample was divided into four subgroups of patients according to which answer category they belonged to. Thus all patients answering to a given questionnaire statement with four (i.e. total agreement) were put into one group. Other groups consisted of patients which had answered with 1, 2, or 3 respectively. For each of these subgroups the average compliance (operationalized as RPBGU-value) of this group was computed. After this was achieved for all 10 single predictor variables, the second step was performed. The item scores of each patient were transformed as follows. Each individual score of every participant (i.e. 1, 2, 3 or 4 for every independent variable) was transformed to the average RPBGU value which had been computed as representative for the group having this score. For the last step, the resulting 10 values for each patient were added. The so formed variable was named IPV because it summarized the 10 predictor scores of each patient. For the whole sample IPV was grouped likewise in four categories that each category comprised approximately the same number of patients. The grouped IPV was cross-tabulated with the grouped RPBGU-values. The resulting diagram together with the Spearman correlation coefficient is shown in Table 6 . The number of

Table 6

Cross-Tabulation of Integrated-Predictor-Variable (IPV) with Relative-Percentage-of-Bleeding-Gingival-Units (RPBGU)

\begin{tabular}{crrrrr}
\multicolumn{5}{c}{ RPBGU } \\
& 1 & 2 & 3 & 4 & total \\
\hline IPV & & & & & \\
4 & 0 & 2 & 3 & 16 & 21 \\
3 & 5 & 4 & 8 & 4 & 21 \\
2 & 4 & 10 & 7 & 2 & 23 \\
1 & 7 & 10 & 4 & 0 & 21 \\
total & 16 & 26 & 22 & 22 & 86 \\
\hline
\end{tabular}

$\Gamma s=0.59 ; \mathrm{P}<0.0001$

IPV $=1$ : group with very positive health beliefs. $\mathrm{RPBGU}=1$ : group with very good compliance. 
cases decreased to 86 because all patients who failed to check off one of the significant items were excluded from computation.

The question asking for barriers to proper oral hygiene was not answered by $52 \%$ of the patients. The others mentioned various reasons which are listed in Table 7.

\section{DISCUSSION}

According to well documented studies, ${ }^{23}$ the decrease in bleeding-tendency from baseline to reevaluation is significantly influenced by changes in oral hygiene behavior of the patients only, and not by the removal of supragingival plaque-retentive factors. Therefore, the use of the RPBGU as a parameter of compliance seems reasonable. However, biological variations exist. The same level of oral hygiene may not be correlated with the same degree of oral health or disease in different people because of their individual susceptibility to periodontal breakdown. ${ }^{24,25}$ This bias can be only partially controlled by computing the relative change in bleeding instead of taking the value at reevaluation alone, and may lower the observed relationship between beliefs and compliance. In our study, however, this bias had only a relatively low influence because all of the patients had periodontitis, i.e. they were susceptible to periodontal breakdown.

When speaking of relationships one has to remember that a significant correlation coefficient is not a proof of causality. However, causality may be assumed for the following reasons: the underlying theoretical model, or the prospective design of the study.

The results of this study corroborate the finding that sociodemographic variables like age, sex, and family standing bear little or no influence on compliance. ${ }^{14}$ The same is true for disease parameters with the exception of TLI. This index, however, is only indirectly related to severity of disease because a lost tooth cannot cause periodontitis. We suggest that TLI should rather be regarded as a measure of "motivation" because it sums up the negligence of the patient or of "experience with affected organ" because tooth loss is certainly a negative experience.

The most important predictors were the health beliefs "motivation" and "perceived severity." "Perceived benefits" and "experience with affected organ" also con-

Table 7

Barriers to Oral Hygiene

\begin{tabular}{lc}
\hline \multicolumn{1}{c}{ Barriers } & $\begin{array}{c}\text { Frequency of } \\
\text { patient responses }\end{array}$ \\
\hline Laziness & 17 \\
Vocational reasons & 14 \\
Lack of time & 11 \\
Lack of information & 7 \\
Other reasons & 7 \\
Costs & 1 \\
No statement & 50 \\
\hline
\end{tabular}

tributed significantly to the resultant behavior. "Perceived susceptibility," "perceived barriers," "dentistpatient-relationship," and "experience with therapy" were not related to compliance. That does not mean the latter variables could not have been significant predictors when operationalized in a different way. Changing the formulations of some statements may lead to different results.

Interestingly $\mathrm{McCaul}$ et al. ${ }^{26}$ also reported difficulties in constructing relevant questions concerning barriers to tooth-brushing behavior. The statements of the patients concerning barriers to proper oral hygiene (see Table 7) also show that there seem to be no specific barriers. The most frequently mentioned reasons (laziness, vocational reasons, lack of time) are certainly not obstacles that can be easily overcome (e.g. by changing the treatment plan). These reasons reflect the patient's estimate that other activities are more important to him than oral hygiene. Hence the dentist has to improve the patient's health beliefs to overcome these barriers. If the patient changes his beliefs and, as a result, values oral cleanliness more than before, he will certainly find a way to integrate the required activities in his day's work. The only mentioned barrier whick can be removed directly by the dentist is "lack of information."

The disappointing results of the items concerning the dentist-patient-relationship may be due to the prospective study design. These items rated patient's faith in the treatment and the belief that cooperation with the dentist will lead to an improvement in oral hygiene. As the questionnaire was filled out prior to any treatment measure, patients could only answer according to their past experiences with dentists. Thus the conclusion can be drawn that former dentist-patient-relationships usually do not influence compliance in a new interaction process.

Altogether this study further supports the assumption that health beliefs play a significant role in the determination of health related behavior. No single predictor has a strong explanatory power. But the combination of the beliefs (IPV) accounts for about one third of the variance of the dependent variable. When looking at Table 6 it can be seen that especially in the two groups with very good and very poor health beliefs respectively, the distinction between compliers and non-compliers is rather successful. None of the 21 patients with very good health beliefs failed totally to comply. However, a certain amount of non-compliance was observed in this group as well. On the other hand the 21 patients with very poor health beliefs were almost complete non-compliers. Only two of them improved their PBGU more than $50 \%$. It is in the two groups with moderately poor/good beliefs where the prediction is more unstable. However, a correlation between beliefs and behavior can still be seen.

Considering the results of this study the following limitations have to be taken into account. 
The study group was not fully randomized. Hence the results can only be transferred to certain populations under similar circumstances.

As is usual in psychological research, beliefs were assessed using a questionnaire. The information gained by this method does not necessarily correspond with the factual beliefs of the patients. Bias may result from social desirability or an inclination of the patient to agree with a given statement. ${ }^{27}$ In order to reduce these influences patients were told in the introduction to the questionnaire that there were no true or false answers but that they were asked only for their opinion.

According to Snyder and Swann, ${ }^{28}$ Regan and Fazio, ${ }^{29}$ and Wilson et al. $^{30}$ several reasons are to be mentioned that may lower the correlation between attitudes and behavior:

-implementation of new attitudes (e.g. through motivation to improve oral hygiene)

-the manner of attitude formation

-competing motives

-situational pressures

-social norms

-variables of personality

Especially by reason of the first mentioned aspects (implementation of new attitudes and manner of attitude formation) the health-educator should also pay attention to health beliefs that did not prove to be significant predictors of compliance in this study or elsewhere. The role of these beliefs in the process of achieving patient adherence still remains unclear. As long as mechanisms leading to the creation of beliefs as well as the stability of beliefs are fields of uncertainty, the health professional should try to positively influence all of the HBM-variables, not restricting himself to the significant predictors.

Research in this area is urgently needed to further clarify the relation between health beliefs and compliance, and the role of modifying influences deriving from the dentist-patient-relationship or the social environment.

In spite of the gaps in our understanding of the processes related to compliance, the health professional should make use of the results of health belief research. Studies engaging in compliance problems in medicine have shown that patients' cooperation is significantly better when methods derived from the framework of the HBM are employed..$^{31,32,33}$ Together with Suedfeld ${ }^{34}$ we "firmly believe that any change that is as drastic and far-reaching as the abandonment of an unhealthy lifestyle and its replacement by a more beneficial one must be based on a reorganization of complex belief-opinion structures."

\section{REFERENCES}

1. Rosling, B., Nyman, S., and Lindhe, J.: The effects of systematic plaque control on bone regeneration in infrabony pockets. J Clin Periodontol 3: 38, 1976.
2. Nyman, S., Lindhe, J., and Rosling, B.: Periodontal surgery in plaque-infected dentitions. J Clin Periodontol 4: 240, 1977.

3. Knowles, J. W., Burgett, F. G., Nissle, R. R., et al.: Results of periodontal treatment related to pocket depth and attachment level. J Periodontol 50: 225, 1979.

4. Ramfjord, S. P., Morrison, E. C., Burgett, et al.: Oral hygiene and maintenance of periodontal support. J Periodontol 53: 26, 1982.

5. Derbyshire, J. C.: Patient motivation in periodontics. $J$ Periodontol 41: 630, 1970.

6. Attstrom, R., Egelberg, J., and von der Fehr, F.: Oral hygiene instruction of the adult patient. In: Frandsen, A., (ed.) Preventive Dentistry in Practice, pp 76-91, Copenhagen, Munksgaard, 1976.

7. Chambers, D. W.: Patient susceptibility limits to the effectiveness of preventive oral health education. JADA 95: 1159, 1977.

8. Meskin, L. H. and Rovin, S.: Do we tell the truth about the prevention and treatment of periodontal disease? J Prev Dentistry 5: 5, 1978.

9. Horowitz, A.: Oral hygiene measures. J Can Dent Assoc 46: 43, 1980.

10. Sheiham, A.: Current concepts in health education. In: Shanley, D., (ed.) Efficacy of Treatment Procedures in Periodontics, pp 23-40, Berlin, Quintessence Publishing Co., Inc., 1980.

11. Oedman, P. A., Lange, A. L., and Bakdash, M. B.: Utilization of locus of control in the prediction of patients' oral hygiene performance. J Clin Periodontol 11: 367, 1984.

12. Sheiham, A.: The prevention and control of periodontal disease. Dent Health 18: 7, 1979.

13. Rosenstock, I. M.: Why people use health services. Milbank Memorial Fund Quarterly 44: 94, 1966.

14. Becker, M. H., and Maimann, L. A.: Sociobehavioral determinants of compliance with health and medical recommendations. Med Care 13: 10, 1975.

15. Haynes, R. B.: A critical review of the 'determinants' of patient compliance with therapeutic regimens. In: Sackett, D. L., and Haynes, R. B., (eds.) Compliance with Therapeutic Regimens, pp 26-39, Baltimore, John Hopkins Press, 1976.

16. Becker, M. H.: Understanding patient compliance: The contributions of attitudes and other psychological factors. In: Cohen, S. (ed.) New Directions in Patient Compliance, pp 1-31, Lexington, Ma., Health, 1979.

17. Eraker, S. A., Kirscht, J. P., and Becker, M. H.: Understanding and improving patient compliance. Ann Intern Med 100: 258, 1984.

18. Kühner, M., and Raetzke, P.: Die Bedeutung des Health Belief Models. der Zahnheilkunde. In: Schneller, T., and Kühner, M., (eds.) Bedeutung der Patientenmitarbeit in der Zahnheilkunde, Köln,Deutscher Aerzte-Verlag, in press.

19. Kirscht, J. P.: Research related to the modification of health beliefs. Health Education Monographs 2: 445, 1974.

20. Lange, D. E., Plagmann, H. C., Eenboom, A., and Promesberger, A.: Klinische Bewertungsverfahren zur Objektivierung der Mundhygiene. Dtsch Zahnärztl Z 32: 44, 1977.

21. Torgerson, W. S.: Theory of Methods and Scaling, New York, Wiley, 1958.

22. Kühner, M.: Eine Prospektive Studie über die Bedeutung des "Health Belief Models" für die Patienten-Compliance bei der systematischen Parodontalbehandlung, Doctoral Thesis, J. W. GoetheUniversity, Frankfurt a.M., 1987.

23. Hetland, L., Midtun, N., and Kristoffersen, T.: Effect of oral hygiene instructions given by para-professional personnel. Community Dent Oral Epidemiol 10: 8, 1982.

24. Van der Velden, U., Winkel, E. G., and Abbas, F.: Bleeding/ plaque ratio-a possible prognostic indicator for periodontal breakdown. J Clin Periodontol 12: 861, 1985.

25. Van der Velden, U., Abbas, F., and Hart, A. A. M.: Experimental gingivitis in relation to susceptibility to periodontal disease. $J$ Clin Periodontol 12: 61, 1985.

26. McCaul, K. D., Glasgow, R. E., and Gustafson, G.: Predicting levels of preventive dental behaviors. JADA 111: 601, 1985.

27. Bortz, J.: Lehrbuch der Empirischen Forschung, Berlin, Sprin- 
ger-Verlag, 1984.

28. Snyder, M., and Swann, W. B.: When action reflect attitudes: The politics of impression management. $J$ Pers and Soc Psych 34: 1034, 1976.

29. Regan, D., and Fazio, R.: On the consistency between attitudes and behavior: Look to the method of attitude formation. $J$ Exp Soc Psych 13: 28, 1977.

30. Wilson, T. D., Dunn, D. S., Bybee, et al.: Effects of analyzing reasons on attitude-behavior consistency. J Pers and Soc Psych 47: 5 , 1984.

30. Haefner, D. P., and Kirscht, J. P.: Motivational and behavioral effects of modifying health beliefs. Public Health Rep 85: 478, 1970.

32. Inui, T. S., Yourtee, E. L., and Williamson, J. W.: Improved outcomes in hypertension after physician tutorials: A controlled trial. Ann Intern Med 84: 646, 1976.
33. Larson, E. B., Bergman, J., Heidrich, F., et al.: Do postcard reminders improve influenza vaccination compliance? A prospective trial of different postcard "cues". Med Care 20: 639, 1982.

34. Suedfeld, P.: Environmental factors influencing maintenance of lifestyle change. In: Stuart, R. B. (ed.) Adherence, Compliance and Generalization in Behavioral Medicine, pp 56-78, New York, Brunner/Mazel Publishers, 1982.

Send reprint requests to: Peter B. Raetzke, D.M.D., M.S.D., Department of Periodontology, University of Frankfurt, Dental School and Clinic "Carolinum," Theodor-Stern-Kai 7, 6000 Frankfurt/M. 70, West Germany.

Accepted for publication 23 April 1988 